\title{
Organic pollutants associated with macromolecular soil organic matter: Mode of binding*
}

\author{
H. H. RICHNOW', R. SEIFERT', J. HEFTER', M. LINK², W. FRANCKE', \\ G. SCHAEFER ${ }^{3}$ and W. MICHAELIS ${ }^{\prime}$ \\ ${ }^{1}$ Institut für Biogeochemie und Meereschemie, Universität Hamburg, Bundesstrasse 55, D-20146 \\ Hamburg, Germany, 'Institut für Organische Chemie, Universität Hamburg, Martin-Luther-King-Platz \\ 6, D-20146 Hamburg, Germany and 'Biotechnologie II, Technische Universität Hamburg-Harburg, \\ Eißendorfer Straße 40, D-21073 Hamburg, Germany
}

(Received 11 June 1996; returned to author for revision 25 July 1996; accepted 19 June 1997)

\begin{abstract}
A study of ether-linked moieties in macromolecular bound residues of polycyclic aromatic hydrocarbons $(\mathrm{PAH})$ generated in bioremediation experiments was performed using high temperature hydrolysis degradation with subsequent analysis of the products by GC-MS. This hydrolysis reaction was specifically designed to cleave ether bonds including relatively stable diarylether structures. Among the reaction products, aromatic alcohols representing typical microbiologically derived metabolites of PAH were found in addition to natural compounds. Thus, parts of the bound residues appeared to be linked within the macromolecular material by ether bonds. Model experiments with an oxidoreductase enzyme and aromatic alcohols indicate the formation of these ether bonds to be an enzyme-catalysed process. (C) 1997 Elsevier Science Ltd
\end{abstract}

Key words-humic substances, soil organic matter, pollutant binding, polycyclic aromatic pollutants, high temperature hydrolysis, bioremediation, ether bond cleavage

\section{INTRODUCTION}

During the past decade, the formation of nonextractable residues (bound residues) from organic pollutants during biodegradation or humification processes in soils has been the subject of increasing scientific interest (e.g. Roberts, 1984; Führ, 1987; Schnöder et al., 1993; Kästner et al., 1995). The association of organic pollutants with macromolecular organic matter via cross-linking reactions has been suggested to be a major sink for organic pollutants in soils (Bollag, 1983). This association has implications for the bioavailability, toxicity, and transport of xenobiotica in natural environments. Recently, we have identified some typical metabolites of PAH chemically bound to soil and riverine humic substances by ester linkages (Richnow et al., 1994; Michaelis et al., 1995). The formation of bound residues by enzyme-catalysed polymerisation

*This paper was presented at the Symposium on Biodegradation of Petroleum (Organizer: Ken Peters) at the American Chemical Society National Meeting in New Orleans, Louisiana, 24-28 March 1996. Acknowledgement is made to the Donors of the Petroleum Research Fund administered by the American Chemical Society for financial support for this symposium.

†To whom correspondence should be addressed. Fax: + 4940 41236347; e-mail: michaelis@geomat.math.unihamburg.de. of phenols including typical pollutants such as halogenated phenols and anilines has been proposed (Berry and Boyd, 1984, 1985; Bollag, 1992; Hatcher et al., 1993). An enzyme-catalysed oxidative crosscoupling between phenolic moieties may be responsible for the formation of ether- and carbon-carbon-bonds within bound residues. However, limited information still exists on the structure of bound residues and a basic understanding regarding the mode of incorporation of contaminants into the macromolecular organic matter is lacking.

To study ether-linked bound residues, a selective chemical degradation method was applied to cleave ether-bonds formed between metabolites of PAH and macromolecular soil humic substances. The products were analysed by GC-MS to elucidate the chemical structure of parts of the non-extractable soil bound residues. The enzyme-catalysed formation of macromolecules was studied using hydroxylated PAH metabolites.

\section{EXPERIMENTAL SECTION}

\section{Samples and methods}

The soil material used for our experiments originates from a pristine Ah-horizon of a Luvisol (Ahhorizon, pseudovergleyte Parabraunerde, German systematic) collected near Hamburg (Berghausen and Goetz, 1993). The slightly loamy soil consists 
of $6.4 \mathrm{wt} . \%$ clay, $15.4 \mathrm{wt} . \%$ silt, and $78.2 \mathrm{wt} . \%$ sand with a maximal water holding capacity of $31.1 \mathrm{wt} . \%$ and an organic carbon content of $1.0 \mathrm{wt} . \%$. The soil samples were spiked $\left(100 \mu \mathrm{g} \mathrm{g}^{-1}\right.$ soil) with naphthalene, phenanthrene, anthracene, fluoranthene, and pyrene, respectively. Prior to spiking, a sub-sample was taken as a control. The spiked sample was incubated in a soil batch reactor for 200 days at $25^{\circ} \mathrm{C}$. For control, a sterilised subsample of the spiked soil was treated likewise in order to evaluate the effect of active microorganisms. Soil samples were periodically analysed for their content of extractable PAH. Details of the incubation procedure are described by Kästner et al. (1995). In a second biodegradation experiment, a tar oil contaminated soil sample from an industrial area in Hamburg was incubated in a bioreactor for 730 days. A $200-\mathrm{kg}$ sample of contaminated soil material was carefully homogenised in a concrete mixer and blended with shredded wheat straw cuttings as an additional carbon source to stimulate microbial activity and to enhance biodegradation. Furthermore, the bioreactor was inoculated with the white rot fungus, Pleurotus ostreatus. At distinct time intervals $(0,14,30,90,180$ and 730 days $)$, samples were taken and stored at $-20^{\circ} \mathrm{C}$ until determination of PAH concentration.

\section{Sample preparation}

The analytical procedure is summarised in Fig. 1. The samples were extensively extracted ultrasonically with organic solvents (toluene/methanol, $4: 1$, v:v). The solvent to soil ratio was $5: 1$ based on

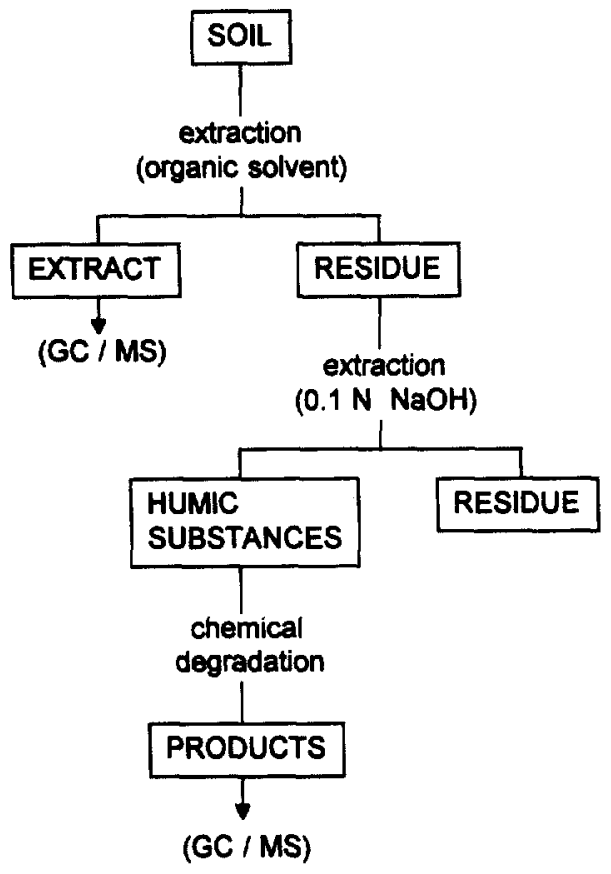

Fig. 1. Analytical flow diagram. volume and the extraction procedure was repeated four times. Soluble compounds were separated by column chromatography $(30 \mathrm{~cm} \times 1 \mathrm{~cm}$, silica gel; Merck 60) to obtain hydrocarbons ( $n$-hexane), aromatic components (n-hexane:toluene, 90:10, v:v) and polar compounds (dichloromethane:methanol: water, 65:25:5, v:v:v).

Organic solvent-extracted soils were dried, extracted five times with $0.1 \mathrm{~N} \mathrm{NaOH}$ solution at $20^{\circ} \mathrm{C}$, and humic acids were precipitated at $\mathrm{pH} 1$ by adding $6 \mathrm{~N} \mathrm{HCl}$ dropwise. Subsequently, the isolated humic acids were subjected to chemical degradation experiments.

\section{Chemical degradation}

A high temperature hydrolysis procedure was modified after Siskin et al. (1991) to cleave diaryl ether bonds. Briefly, a 50-200 mg sample was mixed with $5 \mathrm{ml} 1 \mathrm{~N} \mathrm{HCl}$ solution in a glass ampoule and sealed in a nitrogen atmosphere. The mixture was allowed to react at $315^{\circ} \mathrm{C}$ for $3 \mathrm{~h}$. The products were extracted with diethyl ether prior to chromatographic separation and the organic solvent phase was dried with anhydrous $\mathrm{NaSO}_{4}$. Aromatic alcohols were purified by thin layer chromatography (Merck, silica gel 60) using dichloromethane as developer. The aromatic alcohols were derivatised to trimethylsilyl ethers using bis(trimethylsilyl)trifluoroacetamide (BSTFA).

Oxidative coupling of aromatic alcohols by peroxidase

Aromatic alcohols were dissolved in small amounts of methanol $(2 \mathrm{ml})$ and added to 1 litre of $0.02 \mathrm{M}$ disodium hydrogen phosphate buffer, which was adjusted to a $\mathrm{pH}$ of 8.2 . The slightly alkaline conditions were chosen to enhance the water solubility of polyaromatic alcohols and of humic acids. Concentrations of aromatic alcohols were 5$280 \mathrm{mg}^{-1}$ and the humic acid concentration was $100-800 \mathrm{mg}^{-1} ; 1050 \mathrm{U}$ of horseradish peroxidase (hydrogen peroxide oxidoreductase; EC1.11.1.7 from SERVA, U = ABTS unit definition: one unit oxidises $1 \mu \mathrm{mol}$ of 2,2'-azinobis(3-ethylbenzthiazoline-6-sulfonic acid) per min at $25^{\circ} \mathrm{C}$ and $\mathrm{pH}$ 5.0) were activated with $16.4 \mathrm{mM} \mathrm{H}_{2} \mathrm{O}_{2}$ added dropwise over $5 \mathrm{~min}$. All enzyme-catalysed coupling experiments were carried out at room temperature $\left(20^{\circ} \mathrm{C}\right)$. Typically, the original light brown colour of the reaction mixture changed immediately to dark brown during the activation by $\mathrm{H}_{2} \mathrm{O}_{2}$, indicating a relative, fast reaction.

\section{$G C$ and $G C-M S$ analysis}

Gas chromatographic analyses of the original soil and chemical degradation product extracts were performed on a Carlo Erba gas chromatograph equipped with a fused silica capillary column (DB. $5,30 \mathrm{~m} \times 0.25 \mathrm{~mm}$, J\&W Scientific) and a flame 
ionization detector. The temperature program for the analysis of hydrocarbons and aromatic compounds was: $80^{\circ} \mathrm{C}, 3 \mathrm{~min}$ isothermal; $80-300^{\circ} \mathrm{C}$, $3^{\circ} \mathrm{C} \mathrm{min}{ }^{-1}, 20 \mathrm{~min}$ isothermal; injection mode: on column; carrier gas: $\mathrm{H}_{2}$. GC-MS measurements were performed with a Varian $\mathrm{CH7A}$ mass spectrometer (ionization mode: $\mathbf{E I} ; 70 \mathrm{eV}$ ionisation energy; $250^{\circ} \mathrm{C}$ source temperature; mass range: $\mathrm{m} / \mathrm{z}$ 50-600; resolution 1000) coupled with a Carlo Erba gas chromatograph (carrier gas: $\mathrm{He}$ ) using similar parameters as for the GC measurements. For the quantification of compounds, phenanthrene- $d_{10}$ was used as internal standard. $n$-hexane with phenanthrene- $d_{10}\left(15 \mathrm{mg}^{-1}\right)$ was used to dissolve the respective chromatographic fraction before the GC or GC-MS measurements.

\section{RESULTS AND DISCUSSION}

\section{Bioremediation case study}

A tar oil contaminated field sample was blended with shredded wheat straw cuttings, inoculated with the white rot fungus Pleurotus ostreatus and incubated in a bioreactor for 730 days. The GC trace of the aromatic fraction from the initial material
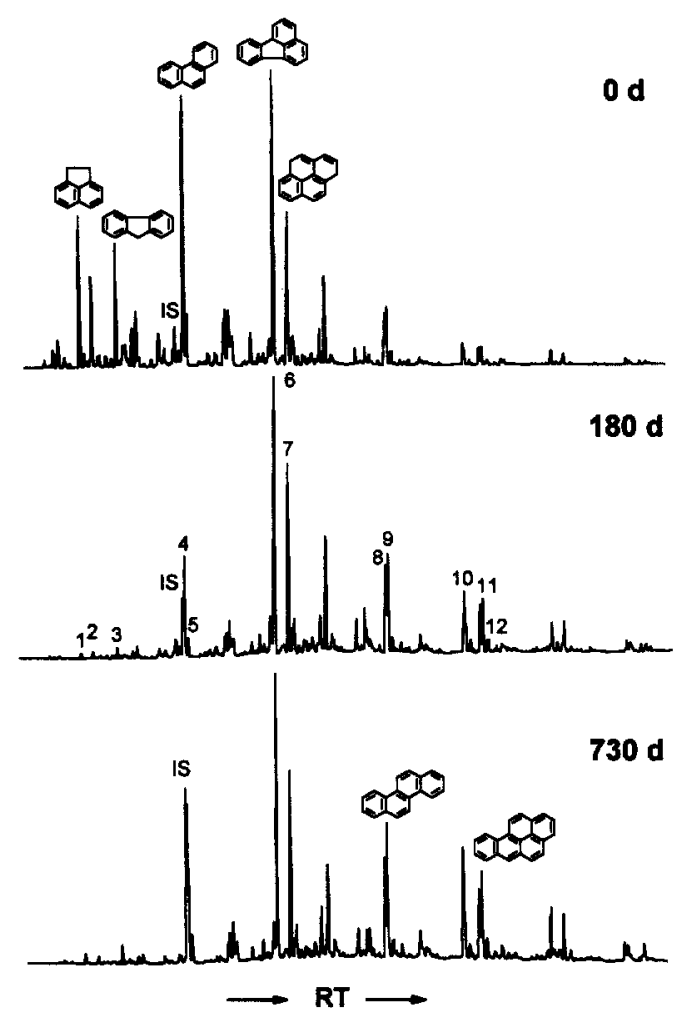

Fig. 2. Gas chromatograms of the aromatic hydrocarbon fraction from the biodegradation experiment of a tar oil polluted soil after 0,180 , and 730 days. For peak identification, see Table 1. IS = internal standard-phenanthrene- $\mathrm{d}_{10}$. Compounds were identified by GC-MS and by coinjection with authentic standards. shows the typical pattern of an aged tar oil characterised by high concentrations of PAH and lower concentrations of their alkylated homologues (Fig. 2, 0 days). Compounds with relatively low boiling points such as naphthalene and alkylated benzenes are already biodegraded or volatilised. During the bioremediation experiment, the concentration of easily biodegradable compounds, i.e. acenaphthene, fluorene and phenanthrene, are significantly reduced while more persistent PAH like benzo $[b, j, k] f$ fluoranthenes, benzo[ $[a, e]$ pyrenes and more highly condensed aromatic compounds became relatively enriched (Fig. 2, 180 days). The quantitative evaluation of PAH-concentrations allows one to classify five PAH-groups according to their biodegradability at least for the experimental set up applied here (Table 1).

1. The most easily degradable compounds such as acenaphthene (1), fluorene (3) and alkylnaphthalenes are characterised by a removal between 99 and $95 \%$.

2. For phenanthrene (4), anthracene (5) and their mono-methylated homologues degradation between 86 and $84 \%$ is observed.

3. Compounds showing intermediate degradation included fluoranthene $(6.77 \%)$, pyrene $(7.68 \%)$, $\mathrm{C}_{2}$-phenanthrenes and $\mathrm{C}_{2}$-anthracenes $(72 \%)$. The lower degradability of the latter compounds as compared to their nonsubstituted homologues indicates that the methyl substitution is reducing the degradability significantly.

4. Benzo[a]anthracene (8) and chrysene (9) are characterised by a degradability between $35 \%$ and $11 \%$, respectively.

5. Benzo $[b, j, k]$ fluoranthenes (10), benzo $[a, e]$ pyrenes (11), perylene (12) and PAH with more condensed carbon skeletons $(m / z 276$ and 278$)$ show no significant removal by microbial processes. Differences in the concentration of contaminants between sub-samples are typical for tar oil contaminated soil sample material. Even if a tar oil contaminated soil is mechanically homogenised and divided into sub-samples, the concentration of contaminants in the sub-samples differs sometimes. This effect may explain differing concentrations of PAH and implies an overall enrichment especially of high molecular weight components during this biodegradation experiment.

Obviously, the resistance of the PAH to biodegradation increases with the molecular weight. Apart from the chemical structure, water solubility is thought to be one of the key factors which strongly influences the bioavailability of these compounds. Corresponding to their low water solubility, the higher molecular weight PAH tend to agglomerate in tar particles modifying bioavailability and biodegradability (Luthy et al., 1993; 
H. H. Richnow et al.

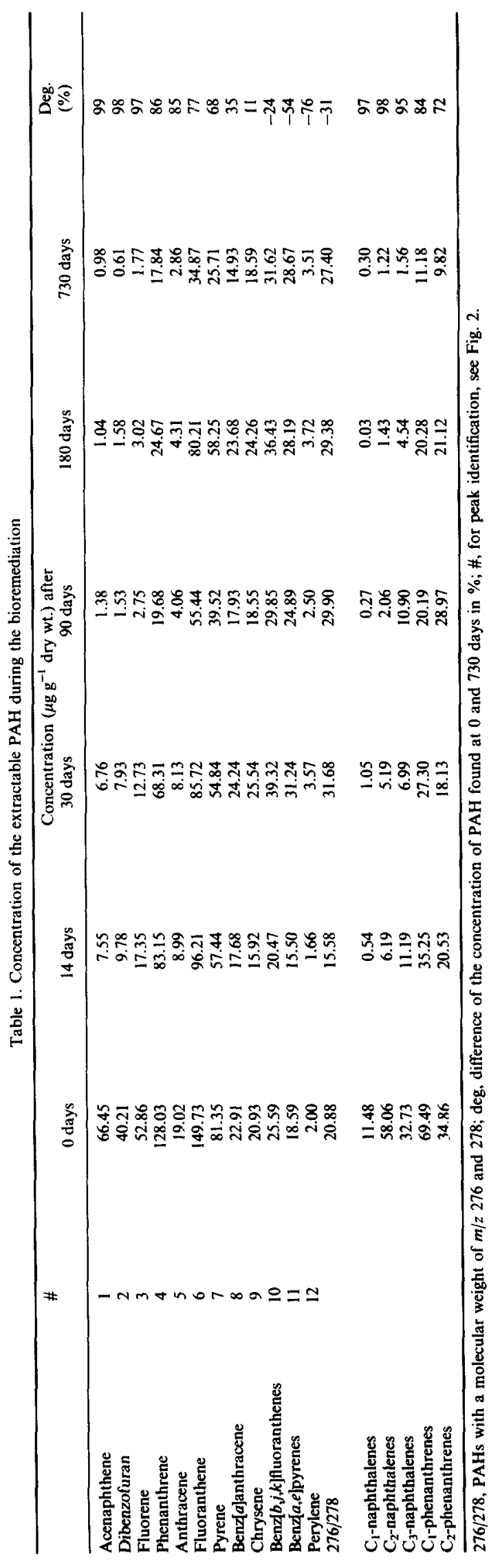


Weißenfels et al., 1993). These particles are typically enriched in layers or tar balls withstanding homogenisation and mixing treatment prior to incubation in the bioreactor.

Easily biodegradable compounds show a fast and efficient removal during the first 30 days to a threshold concentration whereafter the degradation decreases until a final concentration is reached. Then, these PAH were not significantly degraded further indicating a limited bioavailability probably due to an association with tar material. This type of degradation might be typical for compounds which can be actively used by micro-organisms as a source of energy or carbon. The more resistant PAH show a more continuous removal during the entire time of the experiment. The results suggest that these compounds are used to a significantly lower extent as a nutrient.

\section{Biodegradation of an artificially contaminated Ah-} soil

A second biodegradation experiment with an artificially contaminated soil from a pristine Ah-horizon was performed to avoid inferences due to sample inhomogeneity. The soil was spiked with $100 \mu \mathrm{g} \mathrm{g}^{-1}$ of phenanthrene, anthracene, fluoranthene and pyrene, respectively. The concentrations of the PAH declined during the first 200 days of incubation to a final concentration of $0.1-$ $0.5 \mu \mathrm{g} \mathrm{g}^{-1}$ and then remained relatively constant. In detail, $99.9 \%$ of phenanthrene and anthracene and $99.5-99.6 \%$ of fluoranthene and pyrene were removed from the extractable fraction after 200 days (Fig. 3).

In the extract of the sterilised control experiment the recoveries of anthracene, fluoranthene and pyrene ranged from $79 \%$ to $87 \%$ after 200 days and remained constant for the next 600 days. Thus, we conclude that PAH concentrations in the extract of the vital soil were drastically reduced by microbial activity. Compared to the biodegradation of the field contaminated soil, the removal of the added

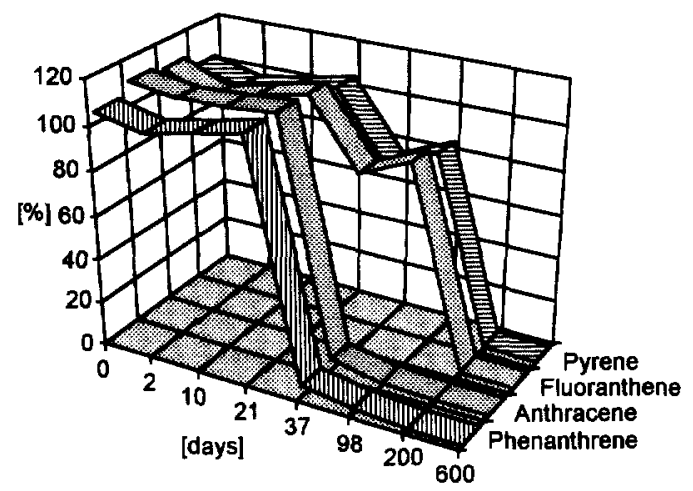

Fig. 3. Concentration of spiked PAH in the biodegradation experiment. (spiked) PAH was more efficient. This may be explained by a difference in bioavailability of the PAH in the spiking experiment because they are dispersed in the soil and not incorporated into tar balls. Furthernore, a minor bioavailability due to adsorption of compounds within humic material or micropores during aging (Hatzinger and Alexander, 1995; Efroymson and Alexander, 1995) may contribute to their lower biodegradation in the contaminated field sample. Support for this suggestion might be taken from similar spiking experiments with ${ }^{14} \mathrm{C}$-labelled compounds wherein incomplete mineralisation to $\mathrm{CO}_{2}$ was observed. A major part of the ${ }^{14} \mathrm{C}$-activity (up to approx. $50 \%$ ) became associated with the solvent-insoluble organic matter in the soil during bioremediation (Kästner et al., 1995).

\section{Chemical degradation}

To elucidate the fate of the soil-bound residues. the humic substances were isolated from the biodegraded soils and subjected to high temperature hydrolysis (modified after Siskin et al., 1990). Figure 4 illustrates the degradation reaction which cleaves ether-bound moieties from humic substances.

The efficiency of the high temperature hydrolysis: was tested with a suite of model compounds (Table 2). Aromatic alcohols are the major cleavage products of the investigated diarylethers. Typical side reaction products in minor yields are corre. sponding aromatic hydrocarbons. Dehydroxylation reactions of polyaromatic phenols are of increasing importance especially in the case of larger polyaromatic systems. For example, the reaction affords naphthalene $(0.4-0.8 \%)$ during the cleavage of naphthyl ether and phenanthrene $(15.2 \%)$ of phenanthryl ether. Elimination reactions have to be considered when interpreting phenanthrol, anthracenol and pyrenol derivatives in chemical degradation products of bound residues. Halogenation of products occurs when $\mathrm{HCl}$ is used to acidify the reaction mixture, but is a side reaction of minor importance. We used $\mathrm{HCl}$ for acidification because we found higher yields and minor amounts of side reaction products compared to phosphoric acid which has been used by Siskin et al. (1991) in simi-

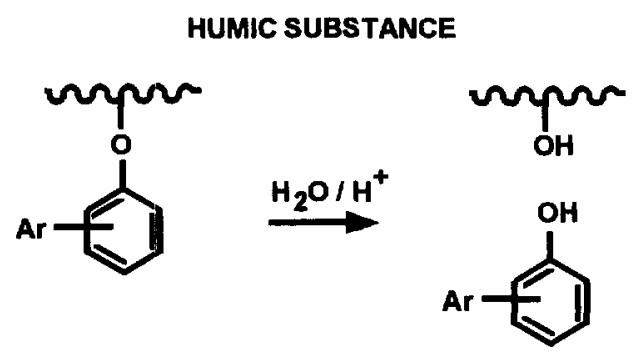

Fig. 4. Chemical degradation of humic substance by high temperature hydrolysis. 
Table 2. Model compounds and their products obtained after high temperature hydrolysis

\begin{tabular}{|c|c|c|}
\hline Substrate & Products & Mol \% \\
\hline \multicolumn{3}{|l|}{ Diphenyl ether } \\
\hline & Diphenylether & 5.8 \\
\hline & Phenol & 183.3 \\
\hline & $C_{1}$-Phenols & 2.5 \\
\hline \multicolumn{3}{|l|}{ 1-Phenylnaphthyl ether } \\
\hline & 1-Naphthol & 91.9 \\
\hline & 2-Naphthol & 3.0 \\
\hline & $\mathrm{C}_{1}$-Naphthols & 1.7 \\
\hline & Naphthalene & 0.8 \\
\hline & $C_{1}$-Naphthalenes & 0.0 \\
\hline & Chloronaphthalene & 1.3 \\
\hline & Phenol & 99.9 \\
\hline \multirow{2}{*}{\multicolumn{3}{|c|}{ 2-Phenylnaphthyl ether }} \\
\hline & & \\
\hline & 2-Naphthol & 84.3 \\
\hline & 1-Naphthol & 0.7 \\
\hline & $\mathrm{C}_{1}$-Naphthols & 13.2 \\
\hline & Naphthalene & 0.4 \\
\hline & $\mathrm{C}_{1}$-Naphthalenes & 1.0 \\
\hline & Chloronaphthalene & 0.4 \\
\hline & Phenol & 85.9 \\
\hline & $\mathrm{C}_{\mathrm{l}}$-Phenols & 14.1 \\
\hline \multicolumn{3}{|l|}{ 9-Phenylphenanthryl ether } \\
\hline & 9-Phenanthrol & 69.8 \\
\hline & Phenanthrols (isom.) & 11.0 \\
\hline & 9-Chloronaphthalene & 2.7 \\
\hline & Phenantherene & 15.2 \\
\hline & $\mathrm{C}_{1}$-Phenantherenes & 1.2 \\
\hline & Phenol & 98.4 \\
\hline & $\mathrm{C}_{1}$-Phenols & 0.7 \\
\hline
\end{tabular}

lar studies. Further model experiments showed that ester bonds are hydrolysed to corresponding acids and alcohols in good yields. The aryl substituted carboxylic group remained reasonably stable in the case of benzoic- and 4-hydroxybenzoic acid (data not shown), and no significant products of secondary alteration were observed. Hydroxylation pro- ducts of aromatic hydrocarbons could not be detected.

Chemical degradation of humic acids isolated from a biodegradation experiment with an artificially contaminated soil

Typically, the degradation reaction of the humic acid yields high concentrations of phenol and a series of alkyl substituted homologues which may characterise the lignin-derived contribution to the humic material (Fig. 5). Alkyl substituted phenols of natural origin are often found in products of chemical degradation and pyrolysis experiments (Mycke and Michaelis, 1986; Hatcher et al., 1988; Hempfling and Schulten, 1990). Furthermore, significant amounts of naphthols and alkylated homologues were observed (Fig. 5). These naphthol derivatives in the humic substances structure may originate from aromatic diterpenoids or other plant tissue compounds with a $\mathrm{C}_{10}$ two-ring carbon backbone. Incomplete biomass burning can also generate PAH carbon skeletons which may subsequently be incorporated into humic substances during humification. The formation of naphthol derivatives during secondary alteration of degradation products from humic substances seems unlikely for several reasons. The pyrolysis of polyunsaturated fatty acids may lead to the formation of alkylated naphthalenes as a result of aromatisation in the course of hydrogen subtraction (Saiz-Jimenez, 1994), but the formation of naphthols and alkylated homologues has not been observed. Furthermore, the carboxylic group remains stable and is not reduced under the conditions described herein as we know from experiments with model compounds

\section{HIGH TEMPERATURE HYDROLYSIS BOUND RESIDUES}

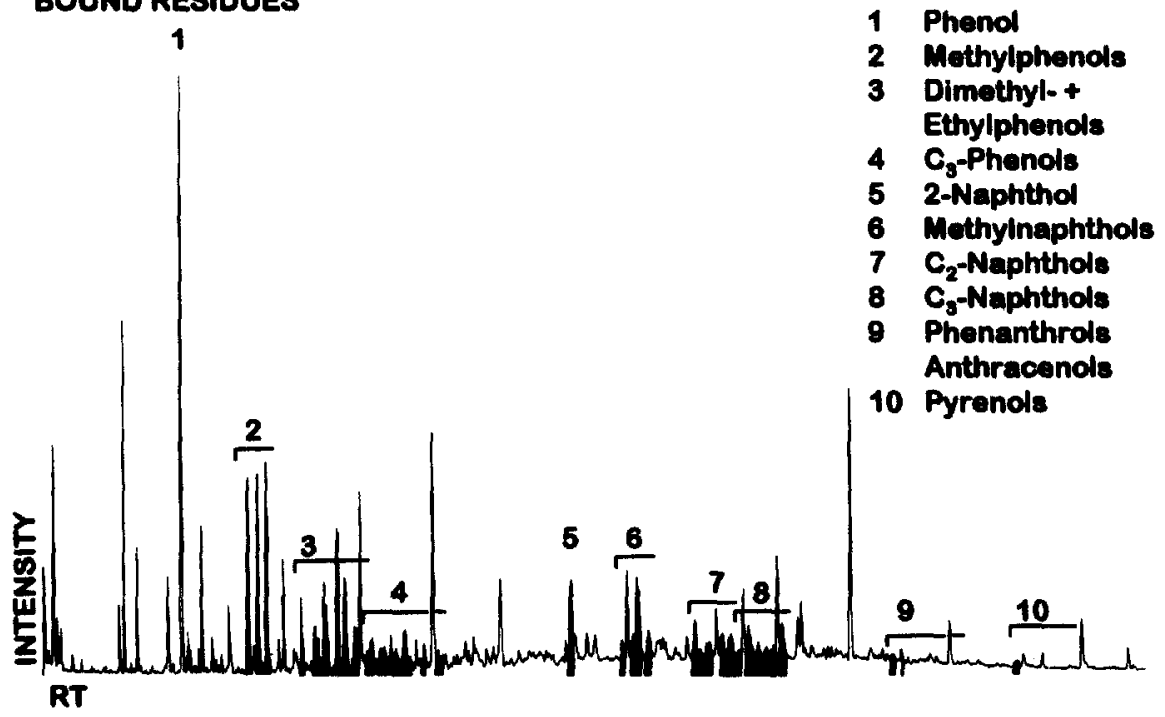

Fig. 5. Gas chromatogram of the aromatic alcohol fraction obtained by high temperature hydrolysis of the humic substance from an artificially contaminated Ah-soil. 
Table 3. Concentration of aromatic alcohols in the products of high temperature hydrolysis of humic substances isolated from the pristine and spiked Ah-soil

\begin{tabular}{lcrr}
\hline & $\begin{array}{c}\text { Ah-soil } \\
(\mu \mathrm{gg} \mathrm{HS})\end{array}$ & $\begin{array}{c}\text { Ah-soil sp } \\
\left(\mu \mathrm{g} \mathrm{g} \mathrm{HS}^{-1}\right)\end{array}$ & $\begin{array}{c}\text { \# } \\
(\%)\end{array}$ \\
\hline Ph, Ant & 0.16 & 2.78 & 1638 \\
Pyrenols & 0.06 & 0.38 & 533 \\
Naphthols & 15.09 & 41.88 & 178 \\
C - Naphthols & 38.33 & 73.29 & 91 \\
C $_{2}$-Naphthols & 29.80 & 66.24 & 122 \\
C $_{3}$-Naphthols & 12.34 & 40.64 & 229 \\
\hline
\end{tabular}

Ph. Ant $=$ phenanthrol and anthracenol isomers, $\mathrm{C}_{1}$-naphthols, methylnaphthols; $\mathrm{C}_{2}$-naphthols, dimethylnaphthols: $\mathrm{C}_{3}$-naphthols, irimethylnaphthols; \#, increase of compounds bound to humic substance $[$ (Ah soil spiked - Ah soil)/Ah soill $\times 100$.

(results not shown). Quantitatively significant condensation or rearrangement reactions of model compounds, leading to the formation of naphthol and phenanthrol derivatives during high temperature hydrolysis, have not been found in our and several other experiments described in Siskin et al. (1990). Consequently, polyaromatic moieties are ether-linked subunits within macromolecular humic material.

Alkylation of aromatic products has been observed when methoxy groups are present. For example, high temperature hydrolysis of methoxy phenols generated small amounts of methyl phenols in experiments with model compounds. This process has been attributed to intramolecular rearrangements (Katritzky et al., 1991). Also, hydrolytic breakdown of humic substances may lead to formation of methylated secondary reaction products. Therefore, the concentration of alkylated phenol and naphthol derivatives in the degradation products might be slightly higher than in the parent humic substance due to rearrangement and methylation reactions. Although there are some uncertainties regarding the origin of the naphthalene carbon skeletons, based on current knowledge, it can be assumed that the concentration of naphthol deriva- tives in the cleavage products reflects their abundance in the parent macromolecule. The natural background concentration of alkylnaphthols in the humic substance of the pristine Ah-soil ranges between 12.3 and $38.3 \mu \mathrm{g} \mathrm{g}^{-1} \mathrm{HS}$ (Table 3). In the humic substance of the spiked Ah-soil, after biodegradation, the concentration of these compounds is 2-3 times higher. Therefore, the major part of these compounds is clearly derived from the added compounds. Functionalised naphthol derivatives are well known microbial metabolites of various PAH (Gibson and Subramanian, 1984). They may become incorporated into the humic substance during the microbial degradation and humification processes.

Beside these compounds, phenanthrols and pyrenols were identified in the chemical degradation products of the humic substance of spiked Ah-soil after biodegradation (Fig. 6). Their concentration exceeds, by several times, the natural background found in the humic substance of the non-spiked soil (Table 3). These compounds were found neither in the solvent extracts of the spiked soil during the biodegradation experiment nor in the solvent extracts of the reference soil. Obviously the phenanthrols and pyrenols did not accumulate

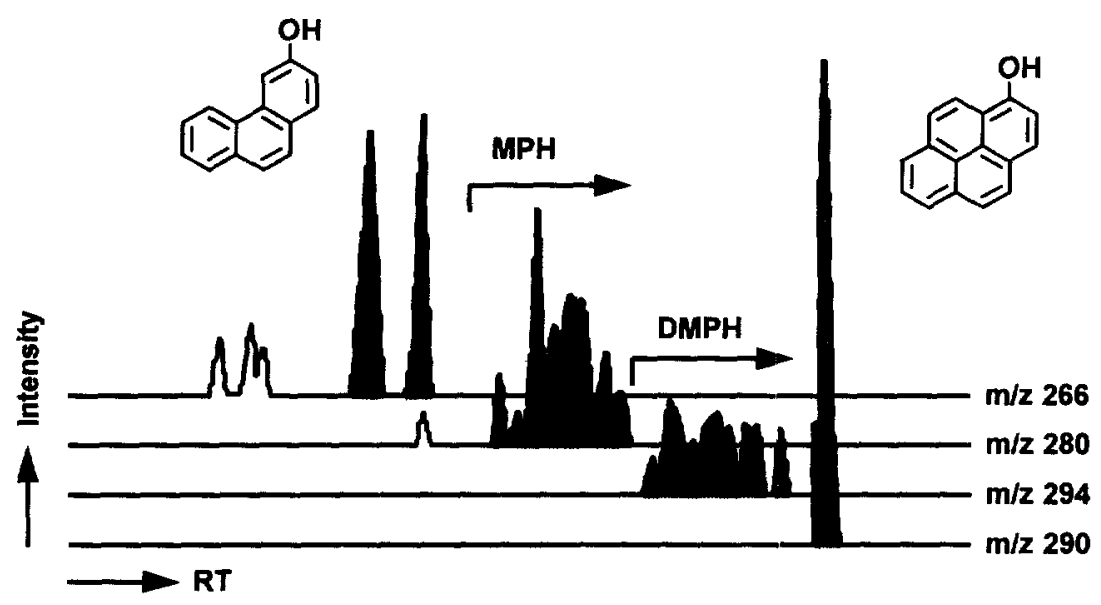

Fig. 6. Partial ion chromatogram of the aromatic alcohol fraction (TMS-ether derivatives) obtained by high temperature hydrolysis of the humic substance from the contaminated soil $(m / z 266=$ phenanthrenol and anthracenol; $m / z 280=C_{1}$-anthracenols and $C_{1}$-phenanthrenols; $m_{i} z 294=C_{2}$-anthracenols and $C_{2}$-phenanthrenols; $m_{i} / z 290=$ pyrenol). 
Table 4. Concentrations of PAH in the spiked Ah-soil at 0 days and after 200 days. Amounts of identified ether- and ester-linked metabolites in humic acids

\begin{tabular}{|c|c|c|c|c|c|c|}
\hline & $\begin{array}{c}\text { Day } 0 \\
\left(\mu \mathrm{g} \mathrm{g}^{-1} \text { soil) }\right.\end{array}$ & $\begin{array}{c}\text { Day } 200 \\
\left(\mu \mathrm{g} \mathrm{g}^{-1} \text { soil }\right)\end{array}$ & $\begin{array}{l}\text { Degraded* } \\
\left(\mu \mathrm{g} \mathrm{g}^{-1} \text { soil) }\right.\end{array}$ & $\begin{array}{l}\text { Ether-linked } \\
\text { alcohols } \\
\left(\mu \mathrm{g} \mathrm{g}^{-1} \text { soil) }\right.\end{array}$ & $\begin{array}{c}\# \\
(\%)\end{array}$ & $\begin{array}{c}\$ \\
(\%)\end{array}$ \\
\hline Phenanthrene & 100 & 0.15 & 99.9 & 0.262 & 0.13 & $0.26+$ \\
\hline Anthracene & 100 & 0.02 & 99.9 & & & \\
\hline Pyrene & 100 & 0.53 & 99.5 & 0.032 & 0.03 & $0.61 \ddagger$ \\
\hline Naphthalene & 100 & $<0.01$ & $>99.9$ & 2.68 & 2.68 & ND \\
\hline
\end{tabular}

* Concentrations of degraded PAH. \#, ether-linked alcohol/amount of degraded PAH $\times 100 . \$$, amounts of ester-linked metabolites were recalculated from Richnow et al. (1994).

$+1+2$-hydroxynaphthoic acids.

¥Phenanthrene-4-carboxylic acid.

during biodegradation in the extractable phase but became incorporated into the humic substance of the soil.

Quantification of ether- and ester-linked PAH metabolites in the humic acid fraction is presented in Table 4. A small part of the total degraded parent pyrene was found as pyrenols $(0.03 \%)$. Phenanthrols and anthracenols, identified in the reaction products, account for $0.13 \%$ of the phenanthrene and anthracene previously added: $2.68 \%$ of the initial naphthalene was recovered as naphthol. The concentrations of phenanthrenol, anthracenol and pyrenol derivatives in the reaction products may underestimate the presence of such ether-linked moieties in bound residues because, with increasing size of the aromatic system the hydroxyl group tends to be eliminated by a secondary reaction mechanism leading to the formation of aromatic compounds. This has been found in degradation reactions with model compounds. In previous studies, we found ester-bound pyrene, anthracene and phenanthrene metabolites in humic substances in concentrations which are in the same order of magnitude (0.26-0.61\%) (Richnow et al., 1994).

Assuming the total amount of soil-bound residues to be about $50 \%$ of the applied PAH, as indicated by ${ }^{14} \mathrm{C}$ experiments, ether-linked components in humic acids identified here account for $0.05-0.25 \%$ of the total bound residues derived from phenanthrene, anthracene and pyrene while the ester- bound moieties account for an additional 0.5$1.25 \%$.

Although ester- and ether-linked metabolites in bound residues identified here are in low concentrations, they already indicate the large structural variety of chemically-bound PAH-metabolites (Table 4). These metabolites reflect the metabolic degradation pathways which are known from pure culture experiments. Furthermore, the fornation of ether and ester bonds associated with the biodegradation of xenobiotics might serve as a model for the early diagenetic formation of geomacromolecules (e.g. humic substances and protokerogens) by biochemically-catalysed processes.

\section{Chemical degradation of humic acids isolated from a contaminated biodegraded soil}

Similar to the spiking experiments, the fraction of aromatic alcohols obtained by high temperature hydrolysis of humic substances from contaminated sites contained a large number of phenolic compounds of natural origin. Additionally, phenanthrols, anthracenols including their alkylated homologues and pyrenols were found in significant concentrations (Table 5). The complex distribution of alkylated phenanthrenol and anthracenol isomers may reflect the complex mixture of alkylated anthracenes and phenanthrenes in the original contaminating tar oil (Fig. 6). Again, during bioremediation these compounds were bound into the humic substance matrix by ether linkages.

Table 5. Concentrations of aromatic alcohois in the high temperature hydrolysis products of humic substances from a tar oil contaminated soil

\begin{tabular}{|c|c|c|c|c|c|}
\hline & \multicolumn{2}{|c|}{0 days } & \multicolumn{2}{|c|}{180 days } & \multirow{2}{*}{$\begin{array}{c}\# \\
(\%)\end{array}$} \\
\hline & $\left(\mu \mathrm{g} \mathrm{g}^{-1} \mathrm{HS}\right)$ & $\left(\mu \mathrm{g} \mathrm{g}^{-1}\right.$ soil $)$ & $\left(\mu \mathrm{g} \mathrm{g}^{-1} \mathrm{HS}\right)$ & $\left(\mu \mathrm{g} \mathrm{g}^{-1}\right.$ soil $)$ & \\
\hline Naphthols & 26.81 & 1.17 & 57.45 & 2.54 & 117 \\
\hline $\mathrm{C}_{1}$-Naphth & 49.88 & 2.17 & 128.74 & 5.69 & 158 \\
\hline $\mathrm{C}_{2}$-Naphth & 17.14 & 0.75 & 92.34 & 4.08 & 439 \\
\hline $\mathrm{C}_{3}$-Naphth & 4.06 & 0.18 & 11.95 & 0.53 & 194 \\
\hline $\mathrm{Ph} / \mathrm{An}$ & 2.86 & 0.12 & 6.24 & 0.28 & 118 \\
\hline $\mathrm{C}_{1} \cdot \mathrm{Ph} / \mathrm{An}$ & 4.18 & 0.18 & 8.48 & 0.37 & 103 \\
\hline $\mathrm{C}_{2}-\mathrm{Ph} / \mathrm{An}$ & 3.83 & 0.17 & 4.10 & 0.18 & 6 \\
\hline $\mathrm{C}_{3}$-Ph/An & 0.83 & 0.04 & 1.04 & 0.05 & 25 \\
\hline
\end{tabular}

$\mathrm{C}_{1^{-}}, \mathrm{C}_{2^{-}}$and $\mathrm{C}_{3^{-}}$Naphth is methyl-, dimethyl- and trimethyl-naphthols; $\mathrm{Ph} / \mathrm{An}$ is phenanthrol and anthracenol isomers; $\mathrm{C}_{1^{-}}, \mathrm{C}_{2^{-}}$and $\mathrm{C}_{3^{-}}$ $\mathrm{Ph} / \mathrm{An}$ is methyl-, dimethyl- and trimethyl phenanthrol and anthracenol isomers; \#, increase of compounds bound to humic substance $\left[\left(\right.\right.$ soil $_{180 \text { days }}-$ soil $\left._{0 \text { days }}\right) /$ soil $\left._{0 \text { days }}\right] \times 100$. 
Table 6. Concentration of PAH in the tar oil contaminated soil at 0 and 180 days

\begin{tabular}{lcccrr}
\hline & $\begin{array}{c}\text { Day } 0 \\
\left(\mu \mathrm{g} \mathrm{g}^{-1} \text { soil }\right)\end{array}$ & $\begin{array}{c}\text { Day } 180 \\
\left(\mu \mathrm{g} \mathrm{g}^{-1} \text { soil }\right)\end{array}$ & $\begin{array}{c}\text { Degraded PAH } \\
\left(\mu \mathrm{g} \mathrm{g}^{-1} \text { soil }\right)\end{array}$ & $\begin{array}{c}\text { Ether linked alcohols } \\
\left(\mu \mathrm{g} \mathrm{g}^{-1} \text { soil }\right)\end{array}$ \\
\hline Phen + Anthr & 147.05 & 28.98 & 118.07 & 0.16 & $\begin{array}{c}\# \\
(\%)\end{array}$ \\
C1-(Phen + Anthr) & 69.49 & 20.28 & 49.21 & 0.19 & 0.14 \\
C2-(Phen + Anthr) & 34.86 & 21.12 & 13.47 & 0.01 & 3.52 \\
C1-Naphthalene & 11.48 & 0.03 & 11.45 & 3.33 & 0.07 \\
C2-Naphthalene & 58.06 & 1.43 & 56.63 & 30.74 & 5.88 \\
C3-Naphthalene & 32.73 & 4.54 & 28.19 & 0.35 & 1.24 \\
\hline
\end{tabular}

\# is (ether-linked alcohol/amount of degraded PAH $\times 100$ ).

The total amount of ether-linked PAH-derived bound residues is in the same order of magnitude as observed in the degradation experiment with the artificially contaminated soil, except for the $C_{1}$ naphthols which may account for $30.7 \%$ of the degraded methyl naphthalenes (Table 6). The reason for the enhanced occurrence of $C_{1}$-naphthols in the degradation products is unknown and is probably not a result of biodegradation-related processes alone.

The initial microbiological oxidation of PAH resulted in dihydrodiols which may be transformed to catechols and phenols. However, phenanthrols, anthracenols and pyrenols have been characterised as typical microbial intermediates which occur during the biodegradation of phenanthrene (Sutherland et al., 1990; Hammel et al., 1992) and anthracene and pyrene (Heitkamp et al., 1988). Hydroxylated PAH are typical metabolic products of corresponding PAH found in higher organisms (Yu et al., 1995). They are formed via enzymatic oxidation of arenes by a cytochrome P450 a yielding monooxygenase enzyme system (Dagley et al., 1972; Yang, 1988; Eisenbrand and Metzler, 1994). Microbial degradation of PAH results in hydroxylated aromatic compounds which are chemically more reactive than their precursors: that is $\mathrm{mi}$ crobial degradation activates the relatively inert PAH by forming functionalized metabolites, such as aromatic alcohols. These compounds may react in natural condensation processes with humic substances to form relatively stable ether bonds.

\section{Enzymatic formation of ethers and carbon-carbon bonds}

The synthesis of arylethers and the formation of carbon-carbon bonds involving alkylation reactions requires anhydrous conditions and higher temperatures. Both are rarely found in soils or sediments. Thus, the formation and abundance of diaryletherand phenyl carbon-carbon-bonds in soil humic material, under natural conditions, cannot be explained by a "classical" synthetic pathway.

More likely, Fenton-type reactions or enzymemediated oxidative polymerisation of phenolic compounds may bind metabolites of $\mathrm{PAH}$ to humic substances via ether- or carbon-carbon-bonds. The enzyme-catalysed polymerisation of phenol derivatives, including typical pollutants such as halogeOG 26/11-12-E nated phenols and anilines, has been proposed as a. major pathway to incorporate xenobiotica into humic material (Bollag, 1983; Hatcher et al., 1993). Berry and Boyd (1984) report structure-activity relationships during oxidative coupling of phenols and anilines by peroxidase. They found that electron donating substituents enhance while electron withdrawing groups hinder the cross-coupling reactions. Chlorinated phenols can be cross-linked to aquatic humic substances in the presence of various oxidoreductases (Sarkar and Bollag, 1987; Sarkar et al., 1988). The enzyme-mediated cross-coupling of xenobiotic substances with humic material may lead to the formation of ether- and C-C-bonds.

To study the structural aspects of polymerization we have analysed the fraction of dimers resulting from a polymerization experiment that treated phenol and 1-naphthol with horseradish peroxidase. A series of hydroxy diaryl ethers and dihydroxy phenyl derivatives were observed (Fig. 7). Major reaction products were dihydroxybiphenyls, and minor products were hydroxydiaryl ethers. 2,2Dihydroxybiphenyl was found to be the major isomer in the dihydroxybiphenyl fraction indicating the ortho-position to be the most reactive site. The precise structures of the hydroxynaphthylphenyl ethers and dihydroxyphenyl naphthalenes have not been elucidated yet, but, analogous to the phenol dimers, the two major isomers in this fraction are supposed to be cross-coupled at the ortho-position to the hydroxy group of 1-naphthol and phenol, respectively.

Enzymatic binding of aromatic alcohols to humic substances

The enzymatic binding of aromatic alcohols (typical metabolites of PAH) to dissolved soil humic substances was tested in a second experiment (Fig. 8).

Soil humic substances were dissolved in a buffer and spiked with selected aromatic alcohols and naphthalene. Horseradish peroxidase was repeatedly added to the mixture and activated with $\mathrm{H}_{2} \mathrm{O}_{2}$. After each step an aliquot of the solution was extracted and analysed. The decrease in the concentration of the added alcohols indicated an efficient binding of these compounds to humic substances. Only naphthalene concentrations remained stable illustrating no significant enzyme-catalysed reactions 


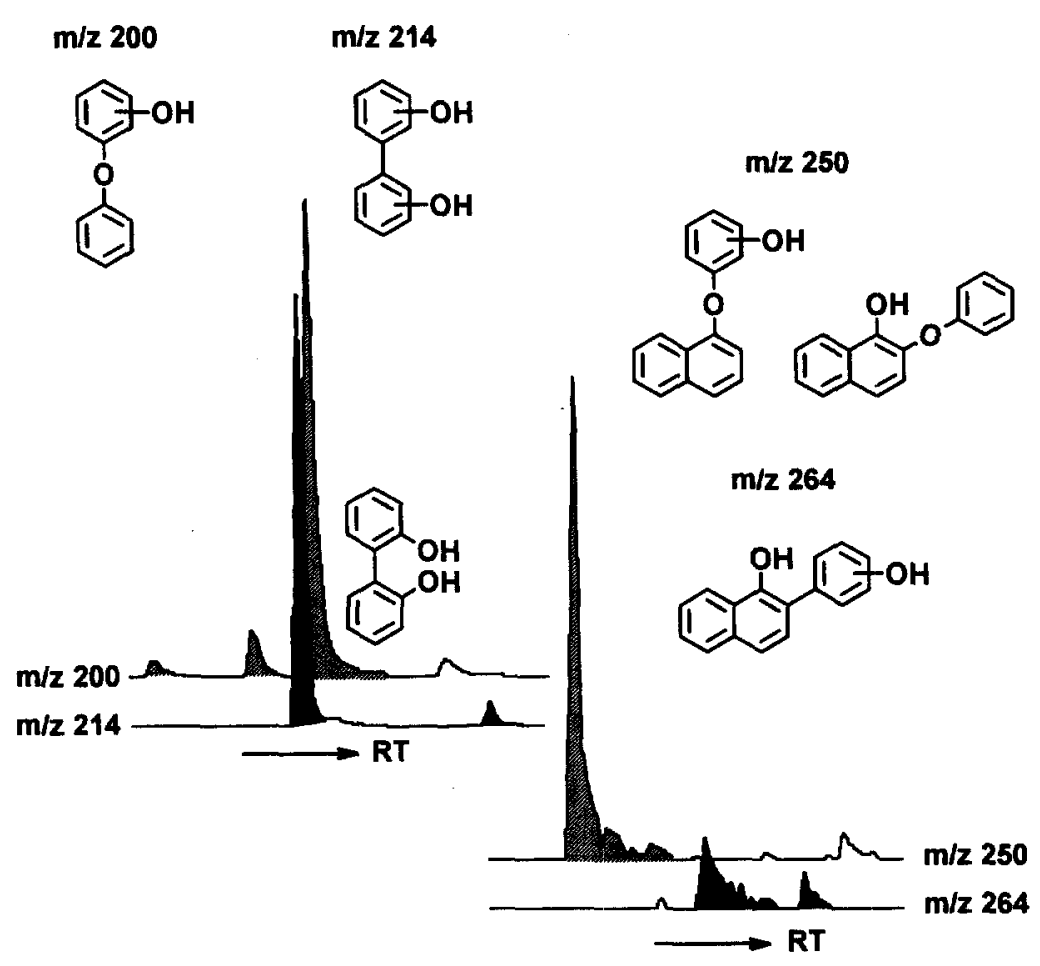

Fig. 7. Partial ion chromatograms of dimeric products (determined as methoxy derivatives) obtained from the enzymatic cross-coupling of 1-naphthol and phenol.

for this compound. The experiments demonstrate that aromatic alcohols undergo peroxidase-mediated cross-coupling reactions and indicate that humic acids serve as a suitable substrate to bind aromatic alcohols.

Furthermore, we compared the enzyme-catalysed cross-linking reactions between naphthol itself and naphthol competing with excess humic substances as a binding substrate (Fig. 9). The ratio of humic substances to naphthol was $5: 1$ based on the dry weight. The decrease in the concentration of extractable naphthol indicates that cross-linking was more effective when the humic substance was present as a binding substrate. Without the added enzyme, no cross-coupling occurred. After 2 days, the reaction products were extracted and the concentrations of GC amenable compounds were determined (Table 7). The concentrations of naphthol and naphthol dimers in the experiment with humic acids were much lower compared to the experiment with-

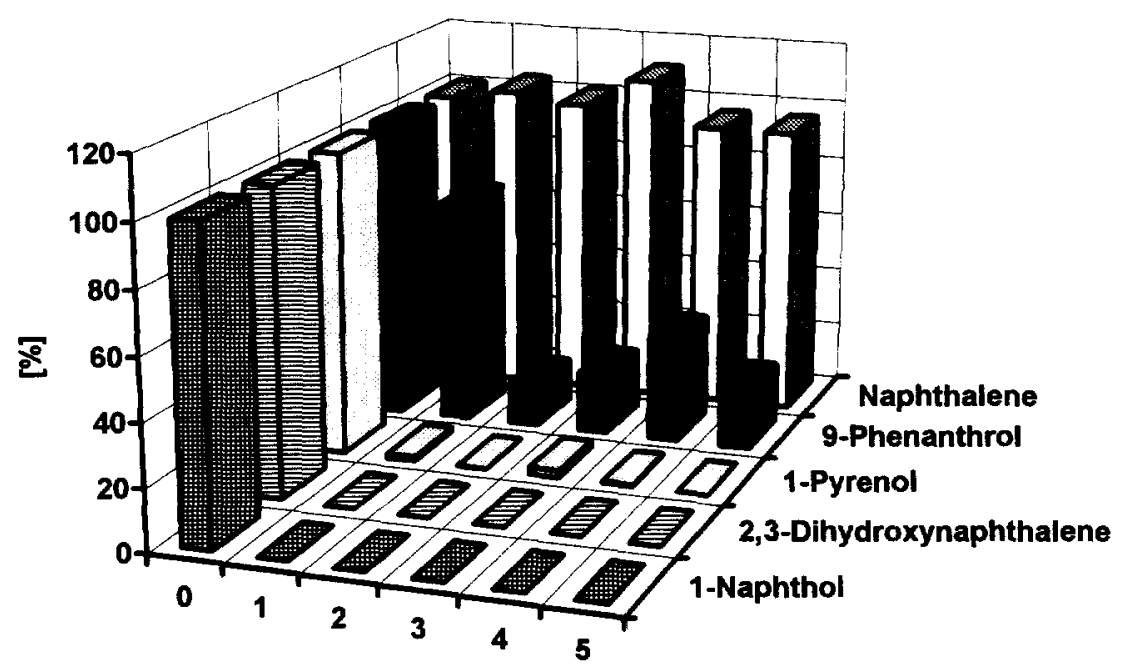

Fig. 7. Enzymatic cross-coupling of aromatic alcohols with soil humic acid. 0, initial analysis before enzyme addition; 1-5, analysis after the repeated addition of activated enzyme. 


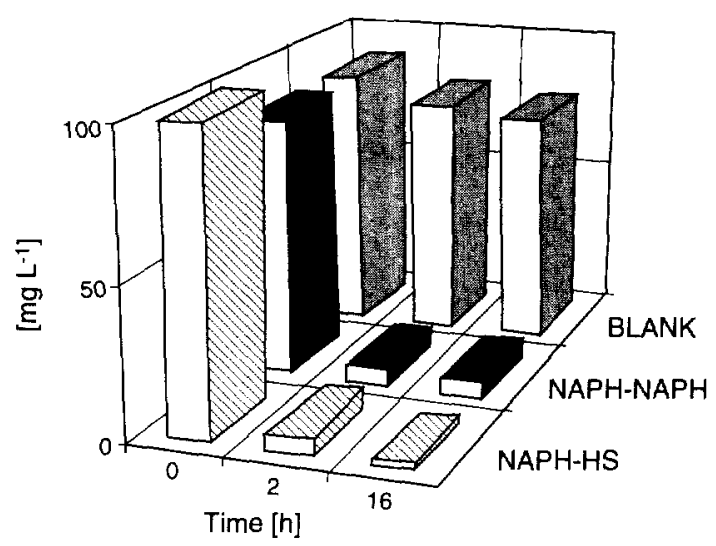

Fig. 9. Concentration of extractable naphthol during the enzymatic cross-coupling with soil humic acid (NAPHNAPH, cross-coupling without humic substance; HS$\mathrm{NAPH}$, cross-coupling in the presence of humic substance. see Table 7).

out humic acid. Furthermore trimeric substances were not present in the cross-coupling experiment with humic substance. This strongly indicates that cross-linking between naphthols forming dimers, oligomers and polymers is not significant when humic substances are present. Humic substance clearly serves as the preferred substrate in the competition for binding sites during enzymatic crosscoupling reactions.

Furthermore, we tested the ability of various structural types of environmentally relevant chemicals to bind to humic substances via enzymatic cross-coupling in an aquatic horseradish $/ \mathrm{H}_{2} \mathrm{O}_{2}$ system. Aliphatic and aromatic hydrocarbons, including halogenated species, remained unaffected by the enzymatic treatment. Previously observed disappearances of halogenated aromatic compounds in similar experiments with polluted waste waters (Klibanov et al., 1983) were probably caused by sorption of these hydrophobic chemicals on humic material and subsequent co-precipitation during the enzymatic treatment.

Fatty acids and aliphatic alcohols also remained stable in the solution during the enzymatic treatment and no significant reactivity was observed for various aromatic acids or ketones. However, all species of aromatic alcohols examined were reactive

Table 7. Concentration of extractable compounds 2 days after the experiments

\begin{tabular}{lcc}
\hline & $\begin{array}{c}\text { NAPH-NAPH } \\
\left(\mu \mathrm{g} \mathrm{l}^{-1}\right)\end{array}$ & $\begin{array}{c}\text { HS-NAPH } \\
\left(\mu \mathrm{g} \mathrm{l}^{-1}\right)\end{array}$ \\
\hline Naphthol & 1563 & 176 \\
Dimers $(m / z$ & 403 & 17 \\
$300+314)$ & 1060 & $>0.5$ \\
Trimers $(m / z$ & & \\
$456+470)$ & &
\end{tabular}

NAPH-NAPH $=$ cross-coupling without humic substance; HS-NAPH $=$ cross-coupling in the presence of humic substance. except 1-hydroxy-2-naphthoic acid (Table 8). Most probably, this is due to the deactivation of the hydroxyl group by the electron withdrawing ortho carboxylic acid (Berry and Boyd, 1984). Electron withdrawing substituents in the para position did not show this effect.

Oxidoreductase enzymes such as peroxidase, laccase and tyrosinase are known to oxidise phenolic compounds to aryloxy radicals, which then polymerise to form insoluble humic acid-like complexes (Martin and Haider, 1980; Sarkar and Bollag, 1987; Bollag et al., 1988; Filip and Preusse, 1985). The kinetics of enzymatic oxidation of phenols and chlorinated derivatives have been studied in various types of soil (Claus and Filip, 1990a). Typical soil constituents can have stimulating or inhibiting effects on the activity of phenoloxidases. Negative effects on the enzyme activity have been observed in the case of substances with high cation exchange capacity such as clays and humic acid complexes (Claus and Filip, 1990b). However, some results; suggest that the association with humic substances might protect enzymes from biodegradation and. denaturation processes. For example, the enzyme activity in humic enzyme complexes is stabilized towards biological, chemical and thermal effects (Nissenbaum and Serban, 1987; Burns, 1989). Summarising current knowledge it seems that in soil and sediment systems, oxidoreductase-like enzymes are suitable microbial-derived catalysts for the formation of ether- and carbon-carbon linkages and thus contribute to the formation of soil-bound residues.

Virtually all higher organisms possess detoxification enzymes which convert lipophilic xenobiotics to water soluble and excretable metabolites as a major excretion and detoxification strategy

Table 8. Horseradish peroxidase catalysed oxidative cross-coupling of model compounds with phenol or humic acids

\begin{tabular}{lc}
\hline Model compounds & Reaction \\
\hline Acids & no \\
Hexadecanoic acid & no \\
1-Hydroxy-2-naphthoic acids & no \\
1-Hydroxybenzoic acid & yes \\
4-Hydroxybenzoic acid & no \\
1-Fluorenoic acid & no \\
2,4-Dichlorobenzoic acid & \\
& \\
Alcohols & no \\
1-Hexadecanol & yes \\
1- and 2-Naphthol & yes \\
2,3-Dihydroxynaphthol & yes \\
9-Phenanthrol & yes \\
1-Pyrenol & yes \\
Phenol & yes \\
Halogenated phenols* & \\
Ketones & no \\
9,10-Phenanthrenechinone & \\
Aromatic hydrocarbons & no \\
Naphthalene &
\end{tabular}

*Data from Sarkar et al. (1988). 


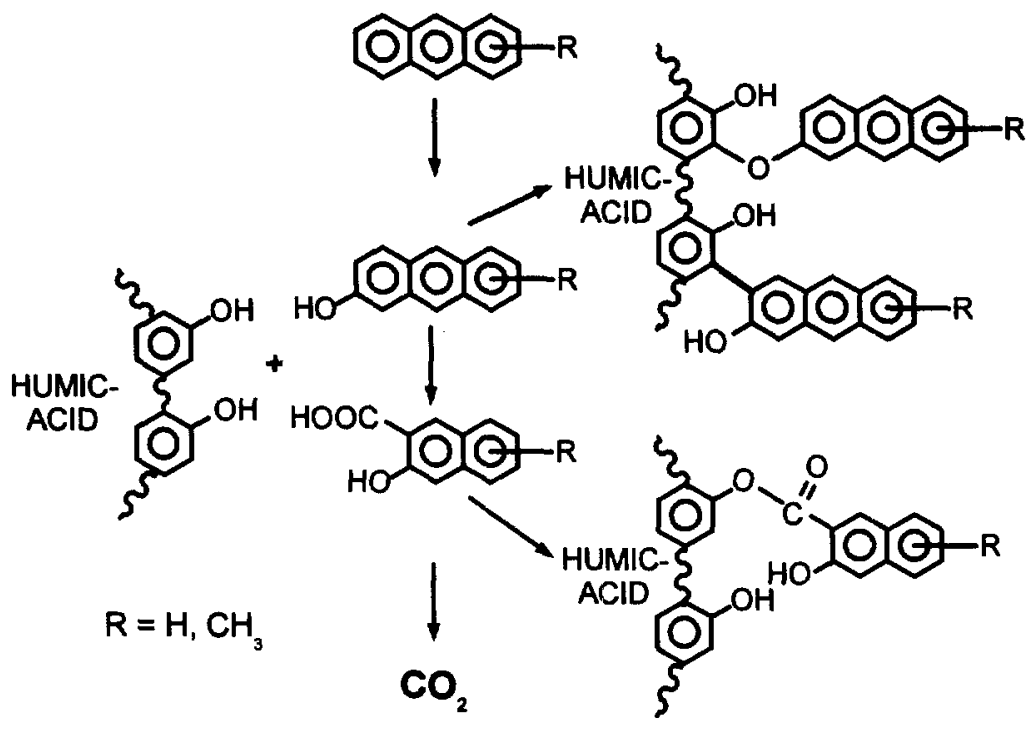

Fig. 10. Scheme of metabolisation of PAH including their alkylated homologues and the interaction with humic substances resulting in the formation of ether- and ester-bonds. Ester-linked bound residues are discussed in detail in Richnow et al. (1994).

(Livingston, 1993). Aromatic hydrocarbons are converted to intermediate arene oxides which then either isomerise to a phenol or undergo enzymatic hydration to a dihydrol (Dagley et al., 1972). These products are converted to highly water soluble substances by conjugation reactions with water soluble moieties (e.g. sulphates, glutathione, or sugar and amino acid derivatives; for a review see Mulder, 1990) which may then be excreted by organelles. Alternatively, metabolites may bind to macromolecular tissue components (Dagley et al., 1972; Yang, 1988). Thus, the major detoxification strategy of higher organisms is to conjugate arene oxides to certain substrates which can be handled, or to immobilise these chemicals to decrease their biological activity. Similarly, microorganisms may use biofilms or humic substances as a substrate to immobilise toxic chemicals. For example, lignindegrading microorganisms secrete phenol polymerising enzymes to bind degraded lignin-derived phenols and detoxify their environment (Grabbe et al., 1968). The formation of covalent-bound residues of xenobiotica may be the result of a comparable polymerisation and detoxification process. The presence of ether-linked xenobiotic moieties in humic substances may indicate that oxidoreductases are involved in such polymerisation processes. In this context, the natural strategy of soil-borne microorganisms to detoxify their habitats by binding toxic substances to humic substances also affects anthropogenic chemicals and may lead to the formation of soil-bound residues. Ether- and carbon-carbon linkages are relatively stable chemical bonds. Therefore, these types of humic substance-bound residues appear to be a sink for anthropogenic chemicals with a relatively low remobilisation potential.

\section{CONCLUSIONS}

Selective chemical degradation of oxygen bonds releases compounds of natural origin and metabolites of organic pollutants from macromolecular soil organic matter and makes them arnenable to $\mathrm{GC} / \mathrm{GC}-\mathrm{MS}$ analysis.

Ether-bound PAH moieties were identified in the reaction products. Their presence implies a reaction of functionalized PAH-metabolites with humic substances to form covalent ether bonds.

Enzyme-catalysed oxidative cross-coupling is a possible process leading to the formation of ethers under typical environmental conditions.

The present knowledge of bound residue formation, exemplified by phenanthrene and alkylated homologues, is summarised in a mode]. (Fig. 10). The metabolisation of PAH leads to the formation of functionalised metabolites which can be incorporated within humic material by the formation of ether-, ester- and carbon-carbon-bonds. The formation of ether bonds is probably an enzyme-catalysed process.

\section{Associate Editor-K. Peters}

Acknowledgements - We thank S. Böhm and U. Tiedgen for the preparation of humic substances. Dr B. Mahro and $\operatorname{Dr} M$. Kästner are acknowledged for providing samples. Our investigations were performed under the auspices of the SFB-188. The financial support from the Deutsche Forschungsgemeinschaft is gratefully acknowledged. 


\section{REFERENCES}

Berghausen, M. and Goetz, D. (1993) Change of soil physical values through oil contaminations. In Contaminated Soils 1993, eds. F. Arend, G. J. Annokkee, R. Bosman and W. J. van den Brink, pp. 907-910. Kluwer, Dordrecht.

Berry, D. F. and Boyd, S. A. (1984) Oxidative coupling of phenols and anilines by peroxidase: structure-activity relationships. Journal of the Soil Science Society of America 48, 565-569.

Berry, D. F. and Boyd, S. A. (1985) Decontamination of soil through enhanced formation of bound residues. Environmental Science and Technology 19, 1132-1133.

Bollag, J. M. (1983) Cross-coupling of humus constituents and xenobiotic substances. In Aquatic and Terrestrial Humic Material, eds. R. F. Christman and E. T. Gjessing, pp. 127-141. Ann Arbor Publishers, Michigan.

Bollag, J. M. (1992) Decontaminating soils with enzymes. Environmental Science and Technology 26, 1877-1881

Bollag, J. M., Shuttleworth, K. L. and Anderson, D. H. (1988) Laccase-mediated detoxification of phenolic compounds. Applied Environmental Microbiology 54, 3086-3091

Burns, R. G. (1989) Microbial and enzyme activities in soil biofilms. In Structure and Function of Biofilms, eds. W. G. Characklis and P. A. Wilderer, pp. 333-349. Wiley, Chichester.

Claus, H. and Filip, Z. (1990a) Effects of clays and other solids on the activity of phenoloxidases produced by some fungi and actinomycetes. Soil Biology and Biochemistry 22, 483-488.

Claus, H. and Filip, Z. (1990b) Enzymatic oxidation of some substituted phenols and aromatic amines, and the behaviour of some phenoleoxidase in the presence of soil related adsorbents. Water Science and Technology 22, 69-77.

Dagley, J. W., Jerina, D. M. and Witkop, B. (1972) Arene oxides and the NIH shift: the metabolism, toxicity and carcinogenicity of aromatic compounds. Experientia 28, 1129-1149.

Efroymson, R. A. and Alexander, M. (1995) Reduced mineralization of low concentration of phenanthrene because of sequestering in nonaqueous-phase lipids. Environmental Science and Technology 29, 515-521.

Eisenbrand, G. and Metzler, M. (1994) Toxikologie für Chemiker-Stoffe, Mechanismen, Prüfverfahren. Georg Thieme, Stuttgart.

Filip, Z. and Preusse, T. (1985) Phenoloxidierende Enzyme-ihre Eigenschaften und Wirkungen im Boden. Pedobiologica 28, 133-142.

Führ, F. (1987) Non-extractable pesticide residues in soil. In Pesticide Science and Biotechnology, eds. $\mathrm{R}$. Greenhalgh and T. R. Roberts, pp. 381-389. Blackwell Scientific Publications, Oxford.

Gibson, D. T. and Subramanian, V. (1984) Microbial degradation of aromatic hydrocarbons. In Microbial Degradation of Organic Compounds, ed. D. T. Gibson, pp. 1281-252. Marcel Dekker, New York.

Grabbe, K., Koenig, R. and Haider, K. (1968) Die Bildung der Phenoloxydase und die Stoffwechselbeeinflussung durch Phenole bei Polystictus versicolor. Archives of Microbiology 63, 133-153.

Hammel, K. E., Gai, W. Z., Green, B. and Moen, M. (1992) Oxidative degradation of phenanthrene by the ligninolytic fungus Phanerochaete chrysosporium. Applied Environmental Microbiology 58, 1832-1838.

Hatcher, P. G., Bortiatynski, J. M., Minard, R. D., Dec, J. and Bollag, J. M. (1993) Use of high resolution ${ }^{13} \mathrm{C}$ NMR to examine enzymatic covalent binding of ${ }^{13} \mathrm{C}$ labelled 2,4 dichlorophenol to humic substances. Environmental Science and Technology 27, 2089-2103.
Hatcher, P. G., Lerch, H. E., Kotra, R. K. and Verheyen, T. V. (1988) Pyrolysis GC-MS of a series of degraded wood and coalified logs that increase in rank from peat to subbituminous coal. Fuel 67, 1069-1075.

Hatzinger, P. B. and Alexander, M. (1995) Effect of aging of chemicals in soil on their biodegradability and extractability. Environmental Science and Technology 29, 537545.

Heitkamp, M. A., Freeman, J. P., Miller, D. W. and Cerniglia, C. E. (1988) Pyrene degradation by a Mycobacterium sp.-Identification of ring oxidation and ring fission products. Applied Environmental Microbiology 54, 2549-2555.

Hempfling, R. and Schulten, H. R. (1990) Chemical characterisation of organic matter in forest soils by Curie Point pyrolysis - GC/MS and pyrolysis-field ionisation mass spectrometry. Organic Geochemistry 15, 131-145.

Kästner, M., Lotter, S., Heerenklage, J., Breuer-Jamali, M., Stegmann, R. and Mahro, B. (1995) Fate of ${ }^{14} \mathrm{C}$ labelled anthracene and hexadecane in compost manured soils. Applied Microbiology and Biotechnology 43, $1128-1135$

Katritzky, A., Murugan, R., Balasubramanian, M. and Siskin, M. (1991) Aqueous high-temperature chemistry of carbo- and heterocycles. 10. Aquathermolysis of acyclic and cyclic phenol ethers in the presence of sodiurn bisulfite or phosphoric acid. Energy and Fuels 5, 543564.

Klibanov, A. M., Tsu, M. T. and Scott, K. P. (1983) Peroxidase-catalyzed removal of phenols from coal-conversion waste waters. Science 221, 259-261.

Livingston, D. (1993) Biotechnology and pollution monitoring: use of molecular biomarkers in the aquatic environment. Journal of Chemical Technology and Biotechnology 57, 195-211.

Luthy, R. G., Ramaswarmi, A., Ghoshal, S. and Merke, W. (1993) Interfacial films in coal tar nonaqueous-phase liquid-water system. Environmental Science and Technology 27, 2914-2918.

Martin, J, P. and Haider, K. (1980) A comparison of the use of phenolase and peroxidase for the synthesis of model humic acid-type polymers. Journal of the Soll Science Society of America 44, 983-988.

Michaelis, W., Richnow, H. H. and Seifert, R. (1995) Chemically bound chlorinated aromatics in humic substances. Naturwissenschaften 82, 139-142.

Mulder, G. J. (ed.) (1990) Conjugation Reaction in Drug Metabolism - An Integrated approach. Substrates, Cosubstrates, Enzymes and their Interaction in Vivo and in Vitro. Taylor and Francis, London.

Mycke, B. and Michaelis, W. (1986) Molecular fossils from chemical degradation of macromolecular organic matter. Organic Geochemistry 10, 847-858.

Nissenbaum, A. and Serban, A. (1987) Enzyme activity associated with humic substances in deep sediments from the Cariaco Trench and Walvis Ridge. Geochimica et Cosmochimica Acta 51, 373-378.

Richnow, H. H., Seifert, R., Hefter, J., Kästner, M., Mahro, B. and Michaelis, W. (1994) Metabolites of xenobiotica and mineral oil constituents linked to macromolecular organic matter in polluted environments. Organic Geochemistry 22, 671-681.

Roberts, T. R. (1984) Non-extractable pesticide residues in soil and plants. Pure and Applied Chemistry 56, 946956.

Saiz-Jimenez, C. (1994) Production of alkylbenzenes and alkylnaphthalenes upon pyrolysis of unsaturated fatty acids. Naturwissenschaften 81, 451-453.

Sarkar, J. M. and Bollag, J. M. (1987) Inhibitory effect of humic and fulvic acids on oxidoreductases as measured by the coupling of 2,4-dichlorophenol to humic sub. 
stances. The Science of the Total Environment 62, 367377.

Sarkar, J. M., Malcolm, R. L. and Bollag, J. M. (1988) Enzymatic coupling of 2,4 dichlorophenol to stream fulvic acid in the presence of oxidoreductase. Journal of the Soil Science Society of America 52, 688-694.

Schnöder, F., Mittelstaedt, M. and Führ, F. (1993) Das Verhalten von Benzo(a)pyrene und Fluoranthen in einer Parabraunerde-Lysimeter und Laborabbaustudien. Biologische Abwasserreinigung 4, 217-230.

Siskin, M., Brons, G., Vaughn, S. N., Katritzky, A. R. and Balasubramania, M. (1990) Aqueous organic chemistry. 3.1,2 Aquathermolysis: reactivity of ethers and esters. Energy \& Fuels 4, 488-492.

Siskin, M., Katritzky, A. R. and Balasubramania, M. (1991) Aqueous organic chemistry, 4. Cleavage of diaryl ethers. Energy \& Fuels 5, 770-771.

Sutherland, J. B., Freeman, J. P., Selby, A. L., Fu, P. P., Miller, D. W. and Cerniglia, C. E. (1990) Stereoselective formation of a K-region dihydrodiol from phenanthrene by Stretomyces flavoviens. Archives of Microbiology 154, 260-266.

Weißenfels, W. D., Klewer, H. J. and Berger, F. (1993) Mikrobielle Abbaubarkeit und Biotoxizität von polyzyklischen Kohlenwasserstoffen (PAK) in Böden. Bioengineering 4, 29-34.

Yang, S. K. (1988) Metabolism and activation of ben$z$ (a)anthracene and methylbenz(a)anthracene. In Polycyclic Aromatic Hydrocarbon Carcinogenesis: Structure-Activity Relationships, eds. S. K. Yang and B. D. Silverman. CRC Press. Boca Raton, FL.

Yu, Y., Wade, T. L., Fang, J., McDonald, S. and Brooks, J. M. (1995) Gas chromatographic-mass spectrometric analysis of polycyclic aromatic hydrocarbon metabolites in Antarctic fish (Notothenia gibberifrons) injected with diesel fuel. Archives of Environmental Contamination and Toxicology 29, 241-246. 